\title{
Structural, thermal and spectroscopic properties of supramolecular coordination solids
}

\author{
BIRINCHI KUMAR DAS, ${ }^{\mathrm{a}, *}$ SANCHAY JYOTI BORA ${ }^{\mathrm{a}}$, \\ MONIDEEPA CHAKRABORTTY, ${ }^{\mathrm{b}}$ LAKSHESWAR KALITA, ${ }^{\mathrm{a}}$ RAJESH CHAKRABARTY ${ }^{\mathrm{a}}$ \\ and RAMAKANTA BARMAN ${ }^{\mathrm{a}, \mathrm{c}}$ \\ ${ }^{a}$ Department of Chemistry, Gauhati University, Guwahati 781014 \\ ${ }^{\mathrm{b}}$ Department of Chemistry, Assam Engineering College, Guwahati 781013 \\ ${ }^{c}$ Present address: Department of Chemistry, Sherubtse College, Royal University of Bhutan, Kanglung, \\ Trashigang, Bhutan \\ e-mail: Birinchi.Das@gmail.com
}

\begin{abstract}
Molecules in metal isonicotinate tetrahydrates, $\mathrm{M}\left(\mathrm{NC}_{5} \mathrm{H}_{4}-p-\mathrm{CO}_{2}\right)_{2} \cdot 4 \mathrm{H}_{2} \mathrm{O}$ with $\mathrm{M}=\mathrm{Mn}, \mathrm{Fe}$, $\mathrm{Co}, \mathrm{Ni}, \mathrm{Cu}, \mathrm{Zn}$, consisting of the hexacoordinate complexes trans- $\left[\mathrm{M}\left(\mathrm{NC}_{5} \mathrm{H}_{4}-p-\mathrm{CO}_{2}\right)_{2}\left(\mathrm{OH}_{2}\right)_{4}\right]$, participate in exhaustive hydrogen-bond formation among themselves to lead to a robust 3D supramolecular network in the solid state. Solid-state diffuse reflectance UV-Vis-NIR spectra of the complexes have been assigned to ligand field and charge transfer transitions. Sharp weight loss due to dehydration, as shown by TGA of $\mathrm{Cu}\left(\mathrm{NC}_{5} \mathrm{H}_{4}-p-\mathrm{CO}_{2}\right)_{2} \cdot 4 \mathrm{H}_{2} \mathrm{O}$, suggests the suitability of this complex for the gravimetric estimation of copper.
\end{abstract}

Keywords. Metal isonicotinate tetrahydrates; 4-pyridine carboxylates; crystal structures; diffuse reflectance UV-visible-NIR studies; applications in gravimetric analysis.

\section{Introduction}

Solubility of ionic salts and coordination complexes of metal ions presents complex behaviour. ${ }^{1}$ If solvent-solute interactions are able to overcome lattice energy effects, the constituent ions or molecules in the crystals disperse uniformly among the solvent molecules. Discrete molecules of neutral coordination compounds often dissolve in water and polar organic solvents provided that the molecular weights of the complexes are not too high. Large molecules present in coordination polymers preclude their solubility in water and common organic solvents, provided that the complexes do not react with the solvent medium as in the case of a ligand substitution reaction involving a solvent molecule. In supramolecular coordination solids the individual molecules may remain associated among themselves via a variety of interactions including $\pi-\pi$ interaction and/or intermolecular hydrogen bonding. ${ }^{2-5}$ If these interactions are not very strong, the cohesive effects holding the molecules together in the crystal lattice may still give in to the solvent effects to result in solubility of the coordination compounds. However, as exempli-

\footnotetext{
*For correspondence
}

fied by the presently discussed complexes, if the number and strength of hydrogen bonds are very high due to the availability of strong hydrogen-bond donors as well as acceptors in the complexes, the very large supramolecules may not disassemble for solubilization. Monocarboxylate anion of isonicotinic or 4-pyridine carboxylic acid (I) is a potentially tridentate ligand and, when it acts as such, leads to the formation of polymeric complexes such as bis(isonicotinato)metal(II). ${ }^{6}$ Coordination of both ends in 4-pyridinecarboxylate occurs under nonaqueous/hydrothermal conditions, ${ }^{6,7}$ while aqueous solutions of metal ions mixed with sodium isonicotinate yield complexes in which only the pyridyl$\mathrm{N}$ atom is coordinated. ${ }^{8}$ The latter situation leaves the dangling carboxyl end $\left(-\mathrm{CO}_{2}^{-}\right)$as a suitable hydrogen bond acceptor as seen in metal(II) isonicotinate tetrahydrates (II). In view of the fact that these complex molecules also contain the coordinated water molecules as excellent hydrogen-bond donors, a very conducive situation for forming intermolecular hydrogen bonds exists. A large number of strong hydrogen bonds sum up to a considerable amount of energy, and as result, a supramolecular coordination solids such as II are likely to display poor solubility in water and common organic solvents. 
<smiles></smiles><smiles></smiles>

In recent years, a variety of supramolecular solids incorporating discrete as well as polymeric coordination complexes have been reported. Apart from their low solubility, such solids may also display properties that are usually not expected from the constituent coordination complexes. Metal isonicotinates have been studied for their nonlinear optical properties ${ }^{9,10}$ as well as selective adsorption capability. ${ }^{11}$ Herein we describe some structural, spectral and thermal properties of a few crystalline solids of composition $\mathrm{M}\left(\mathrm{NC}_{5} \mathrm{H}_{4}-p-\mathrm{CO}_{2}\right)_{2} \cdot 4 \mathrm{H}_{2} \mathrm{O}$ with $\mathrm{M}=\mathrm{Mn}$, $\mathrm{Fe}, \mathrm{Co}, \mathrm{Ni}, \mathrm{Cu}$ and $\mathrm{Zn}$ that have the common property of low or no solubility in water and organic solvents. Molecular structures of these complexes have been reported by other authors. ${ }^{10,12-16}$ Crystal structure analyses on $\mathrm{M}\left(\mathrm{NC}_{5} \mathrm{H}_{4}-p-\mathrm{CO}_{2}\right)_{2} \cdot 4 \mathrm{H}_{2} \mathrm{O}$ with $\mathrm{M}=\mathrm{Mn}$, $\mathrm{Fe}, \mathrm{Co}, \mathrm{Ni}, \mathrm{Cu}$ and $\mathrm{Zn}$ have also been performed by us. ${ }^{17}$ Crystal and molecular structures determined by us for $\mathrm{Cu}\left(\mathrm{NC}_{5} \mathrm{H}_{4}-p-\mathrm{CO}_{2}\right)_{2} \cdot 4 \mathrm{H}_{2} \mathrm{O}$ are discussed in some detail in this paper, particularly to highlight the intermolecular hydrogen bonding effects.

Primarily the crystal structures of [M(isonicotinate $\left.)_{2}\left(\mathrm{OH}_{2}\right)_{4}\right]$, i.e. $\mathrm{M}\left(\mathrm{C}_{6} \mathrm{H}_{4} \mathrm{O}_{2} \mathrm{~N}\right)_{2}\left(\mathrm{H}_{2} \mathrm{O}\right)_{4}$ as hexacoordinate complexes were discussed in earlier publiccations, although thermal decomposition behaviour and powder diffraction data on $\mathrm{Cu}\left(\mathrm{C}_{6} \mathrm{H}_{4} \mathrm{O}_{2} \mathrm{~N}\right)_{2}$ $\left(\mathrm{H}_{2} \mathrm{O}\right)_{4}$ have been reported. ${ }^{18}$ No general synthetic methodology for metal isonicotinate tetrahydrates has been reported so far. Detailed magnetic and spectroscopic properties of the compounds have not also been studied. Herein we report their high yield syntheses, room temperature magnetic moments of the anticipated paramagnetic species along with the diffuse reflectance UV-visible-NIR spectral data on these complexes for the first time. We also discuss the thermal stability of these complexes, by taking $\mathrm{Cu}\left(\mathrm{C}_{6} \mathrm{H}_{4} \mathrm{O}_{2} \mathrm{~N}\right)_{2}\left(\mathrm{H}_{2} \mathrm{O}\right)_{4}$ as an example, to explore the use of these sparingly soluble compounds for the purpose of quantitative metal analysis by the gravimetric method.

\section{Experimental}

All materials used in this work were obtained from commercial sources and used without purification.
UV-visible-NIR (200-2600 nm) diffuse-reflectance spectra were obtained using a Shimadzu UV-3101PC scanning spectrophotometer. $\mathrm{BaSO}_{4}$ powder was used as reference (100\% reflectance). Absorption data were calculated from the reflectance data using the Kubelka-Munk function $\left(a / S=(1-R)^{2} / 2 R\right.$ where $a$ is the absorption coefficient, $R$ the reflectance and $S$ the scattering coefficient). ${ }^{19}$ Solution UV-visible spectra were obtained using a Perkin-Elmer Lambda 40 spectrophotometer in the $200-1100 \mathrm{~nm}$ range. Thermogravimetric (TG) studies were carried out using a Shimadzu TGA-50 thermal analyser. Thermal decomposition behaviour was determined by increasing sample temperature at the rate of $10 \% \mathrm{~min}$ in an atmosphere of dry nitrogen gas flowing at the rate of $20 \mathrm{ml} / \mathrm{min}$. Magnetic moments were calculated from magnetic susceptibilities (corrected for diamagnetism) measured using a Sherwood MK-1 tabletop magnetic susceptibility balance. X-ray crystallographic procedures are described below in a separate section.

\subsection{Preparation of $\mathrm{M}\left(\mathrm{C}_{6} \mathrm{H}_{4} \mathrm{O}_{2} \mathrm{~N}\right)_{2}\left(\mathrm{H}_{2} \mathrm{O}\right)_{4}$ $(\mathrm{M}=\mathrm{Mn}, \mathrm{Fe}, \mathrm{Co}, \mathrm{Ni}, \mathrm{Cu}, \mathrm{Zn})$}

Neutralized 4-pyridine carboxylic acid (isonicotinic acid) is reacted with an appropriate salt of the above metals and the reaction mixture is stirred for $2-4 \mathrm{~h}$. The microcrystalline product formed is filtered, washed with water followed by rectified spirit and diethyl ether and dried in air. Yield: $\sim 70 \%(\mathrm{M}=\mathrm{Fe}$, $\mathrm{Co}) ; \sim 100 \%(\mathrm{M}=\mathrm{Mn}, \mathrm{Ni}, \mathrm{Cu}, \mathrm{Zn})$. Metal analyses performed by classical analytical techniques showed the assumed molecular formulas to be correct. Magnetic moments determined for the complexes at room temperatures gave expected values except for $\mathrm{Fe}\left(\mathrm{C}_{6} \mathrm{H}_{4} \mathrm{O}_{2} \mathrm{~N}\right)_{2}\left(\mathrm{H}_{2} \mathrm{O}\right)_{4}$ and $\mathrm{Zn}\left(\mathrm{C}_{6} \mathrm{H}_{4} \mathrm{O}_{2} \mathrm{~N}\right)_{2}\left(\mathrm{H}_{2} \mathrm{O}\right)_{4}$ which are diamagnetic (table 1 ).

Table 1. Metal contents and effective magnetic moments of $\mathrm{M}\left(\mathrm{C}_{6} \mathrm{H}_{4} \mathrm{O}_{2} \mathrm{~N}\right)_{2}\left(\mathrm{H}_{2} \mathrm{O}\right)_{4}(\mathrm{M}=\mathrm{Mn}, \mathrm{Fe}, \mathrm{Co}, \mathrm{Ni}$, $\mathrm{Cu}, \mathrm{Zn})$.

\begin{tabular}{lccc}
\hline $\mathrm{M}$ & $\% \mathrm{M}$ (calc.) & $\% \mathrm{M}$ (obsd.) & $\mu_{\text {eff }}(\mathrm{BM})(298 \mathrm{~K})$ \\
\hline $\mathrm{Mn}$ & 14.81 & $14 \cdot 50$ & $5 \cdot 67$ \\
$\mathrm{Fe}$ & $15 \cdot 01$ & 14.65 & $\chi_{g}=-0.114 \times 10^{-6} \mathrm{cgsu}$ \\
$\mathrm{Co}$ & $15 \cdot 71$ & $15 \cdot 03$ & 4.74 \\
$\mathrm{Ni}$ & 15.66 & $15 \cdot 24$ & $3 \cdot 15$ \\
$\mathrm{Cu}$ & 16.74 & 16.26 & 1.79 \\
$\mathrm{Zn}$ & $17 \cdot 14$ & 16.86 & Not measured \\
\hline
\end{tabular}




\section{$2.2 X$-ray crystallographic procedures}

Molecular and crystal structures of $\mathrm{Cu}\left(\mathrm{C}_{6} \mathrm{H}_{4} \mathrm{O}_{2} \mathrm{~N}\right)_{2}$ $\left(\mathrm{H}_{2} \mathrm{O}\right)_{4}$ and the corresponding complexes of $\mathrm{Mn}, \mathrm{Fe}$, $\mathrm{Co}$ and $\mathrm{Ni}$ were determined by the single-crystal $\mathrm{X}$ ray diffraction technique. To obtain suitable crystals for single-crystal $\mathrm{X}$-ray diffraction work an aqueous solution of cupric sulphate was mixed with a neutralized aqueous solution of isonicotinic acid and the resulting mixture was left undisturbed for two days. Other single crystals were prepared by suitable solution techniques including slow diffusion. Crystals of the copper and other compounds mounted on fine glass fibre were used for intensity data collection using graphite monochromatized Mo-K $\alpha(\lambda=0.71073 \AA)$ radiation on a Bruker SMART Platform CCD diffractometer. Several sets of frames covering a random area of the reciprocal space were collected using $0.3^{\circ}$ steps in $\omega$ at a detector to sample distance of $\sim 5 \mathrm{~cm}$. SMART software ${ }^{20}$ was used for data acquisition and SAINT ${ }^{21}$ for data extraction and reduction. The empirical absorption corrections were applied on the data with SADABS ${ }^{22}$ and structure solution and refinement were carried out using SHELXS-97 and SHELXL-97 respectively. ${ }^{23}$

The correct assignment of the triclinic centrosymmetric space group for the crystal structure was made on the basis of successful solution and wellbehaved refinement of the structures. All atoms except the hydrogen atoms were refined anisotropically. The hydrogen atoms were located in difference Fourier maps and refined with isotropic displacement parameters. Structural diagrams were generated using the programs ORTEP-3 and PLUTON incorporated in WinGX. ${ }^{24}$

\section{Results and discussion}

The tetraaquabis(isonicotinato)metal(II) complexes with metal $=\mathrm{Mn}, \mathrm{Fe}, \mathrm{Co}, \mathrm{Ni}, \mathrm{Cu}, \mathrm{Zn}$ have been prepared following a high yield general route at room temperature. In this procedure a neutralised aqueous solution of isonicotinic acid is treated with a suitable $\mathrm{M}^{2+}$ salt to obtain the desired products as precipitates. The crystalline compounds are characteristically coloured, air-stable and moisture-insensitive solids that are insoluble in water and common organic solvents. However, the bright yellow colour of the airstable iron(II) compound, $\mathrm{Fe}\left(\mathrm{C}_{6} \mathrm{H}_{4} \mathrm{O}_{2} \mathrm{~N}\right)_{2}\left(\mathrm{H}_{2} \mathrm{O}\right)_{4}$, is quite notable. In addition, the negative magnetic susceptibility observed for this compound suggests a low-spin ${ }^{1} A_{1 g}$ ground state instead of the more usual ${ }^{5} T_{2 g}$ ground state for iron(II). The $\mu_{\text {eff }}$ values observed for the paramagnetic species, i.e. $\left[\mathrm{M}\left(\mathrm{C}_{6} \mathrm{H}_{4} \mathrm{O}_{2} \mathrm{~N}\right)_{2}\right.$ $\left.\left(\mathrm{H}_{2} \mathrm{O}\right)_{4}\right]$ with $\mathrm{M}=\mathrm{Mn}(5.67 \mathrm{BM}), \mathrm{Co}(4.74 \mathrm{BM}), \mathrm{Ni}$ $(3.15)$ and $\mathrm{Cu}(1.79 \mathrm{BM})$ are all in the expected ranges ${ }^{1}$ for high-spin $d^{5}-\mathrm{Mn}^{2+}(5 \cdot 65-6 \cdot 10 \mathrm{BM})$, high-spin $d^{7}-\mathrm{Co}^{2+}(4 \cdot 30-5 \cdot 20 \mathrm{BM}), d^{8}-\mathrm{Ni}^{2+}(2 \cdot 80-$ $3.50 \mathrm{BM})$ and $d^{9}-\mathrm{Cu}^{2+}(1 \cdot 70-2 \cdot 20 \mathrm{BM})$ respectively.

\subsection{Crystal structures}

The molecular structure of $\mathrm{Cu}\left(\mathrm{C}_{6} \mathrm{H}_{4} \mathrm{O}_{2} \mathrm{~N}\right)_{2}\left(\mathrm{H}_{2} \mathrm{O}\right)_{4}$ has been determined by X-ray diffraction. An ORTEP diagram for the molecule is shown in figure 1 . The copper atom lying at the crystallographic and molecular centre of inversion $(0,0,0)$ is six-coordinate with four water molecules and two isonicotinate anions present as ligands. The coordination sphere is considerably distorted due to the Jahn-Teller effect to lead to the familiar $(4,2)$ coordination geometry around copper(II). The two trans isonicotinato ligands coordinate to copper via its pyridyl-N $(\mathrm{Cu} 1-$ N1: 2.006(1) $\AA$ ) atoms leaving the carboxylate groups free. While the $\mathrm{Cu} 1-\mathrm{O} 1$ distance of $1.986(1) \AA$ is normal, the $\mathrm{Cu} 1-\mathrm{O} 2$ distance of $2.452(2) \AA$ is considerably elongated. The cis bond angles in the coordination sphere range between $94.01(7)^{\circ}$ and $85.99(7)^{\circ}$, while the trans angles are all exactly $180^{\circ}$ because of symmetry requirements. As a result, the four-fold axis of the approximate $D_{4 h}$ symmetry around the copper atom is along the $\mathrm{O} 2-\mathrm{Cu}-\mathrm{O}^{\prime}$ ' direction, which is perpendicular to the plane formed by $\mathrm{O} 1, \mathrm{~N} 1, \mathrm{O}^{\prime}, \mathrm{N1}^{\prime}$ and $\mathrm{Cu}$. Owing to symmetry restrictions this is a perfect plane.

Molecular structures of the analogous compounds formed by $\mathrm{Mn}, \mathrm{Fe}, \mathrm{Co}, \mathrm{Ni}$ and $\mathrm{Zn}$ are very similar to that of $\mathrm{Cu}\left(\mathrm{C}_{6} \mathrm{H}_{4} \mathrm{O}_{2} \mathrm{~N}\right)_{2}\left(\mathrm{H}_{2} \mathrm{O}\right)_{4}$, except for the absence of the two long bonds along the $C_{4}$ axis in the coordination sphere. ${ }^{17}$ Selected structural data obtained by us for $\mathrm{Cu}\left(\mathrm{C}_{6} \mathrm{H}_{4} \mathrm{O}_{2} \mathrm{~N}\right)_{2}\left(\mathrm{H}_{2} \mathrm{O}\right)_{4}$ are given in table 2 .

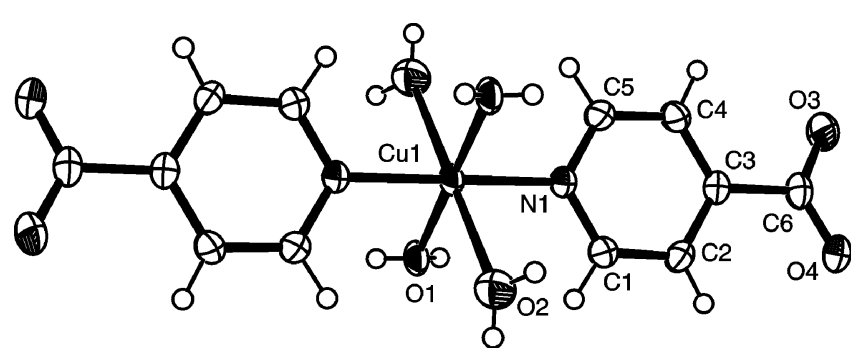

Figure 1. An ORTEP diagram of $\mathrm{Cu}\left(\mathrm{C}_{6} \mathrm{H}_{4} \mathrm{O}_{2} \mathrm{~N}\right)_{2}\left(\mathrm{H}_{2} \mathrm{O}\right)_{4}$ showing non-hydrogen atoms by ellipsoids drawn at $50 \%$ probability level. 
Table 2. Bond lengths $[\AA]$, angles $\left[^{\circ}\right]$ and hydrogen bonds for $\mathrm{Cu}\left(\mathrm{C}_{6} \mathrm{H}_{4} \mathrm{O}_{2} \mathrm{~N}\right)_{2}\left(\mathrm{H}_{2} \mathrm{O}\right)_{4}$.

\begin{tabular}{|c|c|c|c|c|}
\hline \multicolumn{5}{|l|}{ Bond distances } \\
\hline $\mathrm{Cu}(1)-\mathrm{O}(1)$ & $1.9864(14)$ & $\mathrm{Cu}(1)-\mathrm{N}(1)$ & $2 \cdot 0059(15$ & \\
\hline $\mathrm{Cu}(1)-\mathrm{O}(2)$ & $2 \cdot 4525(17)$ & $\mathrm{O}(3)-\mathrm{C}(6)$ & $1 \cdot 253(2)$ & \\
\hline $\mathrm{O}(4)-\mathrm{C}(6)$ & $1 \cdot 248(2)$ & & & \\
\hline \multicolumn{5}{|l|}{ Bond angles } \\
\hline $\mathrm{O}(1)-\mathrm{Cu}(1)-\mathrm{N}(1)$ & $89 \cdot 91(6)$ & $\mathrm{O}(1) \# 1-\mathrm{Cu}(1)-\mathrm{N}(1)$ & $90 \cdot 09(6)$ & \\
\hline $\mathrm{O}(1)-\mathrm{Cu}(1)-\mathrm{N}(1) \# 1$ & $90 \cdot 09(6)$ & $\mathrm{O}(1)-\mathrm{Cu}(1)-\mathrm{O}(2) \# 1$ & $85 \cdot 99(7)$ & \\
\hline $\mathrm{N}(1)-\mathrm{Cu}(1)-\mathrm{O}(2) \# 1$ & $91 \cdot 16(6)$ & $\mathrm{O}(1)-\mathrm{Cu}(1)-\mathrm{O}(2)$ & $94 \cdot 01(7)$ & \\
\hline $\mathrm{O}(1) \# 1-\mathrm{Cu}(1)-\mathrm{O}(2)$ & $85 \cdot 99(7)$ & $\mathrm{N}(1)-\mathrm{Cu}(1)-\mathrm{O}(2)$ & $88 \cdot 84(6)$ & \\
\hline $\mathrm{N}(1) \# 1-\mathrm{Cu}(1)-\mathrm{O}(2)$ & $91 \cdot 16(6)$ & $\mathrm{O}(4)-\mathrm{C}(6)-\mathrm{O}(3)$ & $125 \cdot 9(2)$ & \\
\hline \multicolumn{5}{|l|}{ Hydrogen bonds } \\
\hline $\mathrm{D}-\mathrm{H} \cdots \mathrm{A}$ & $d(\mathrm{D}-\mathrm{H})$ & $d(\mathrm{H} \cdots \mathrm{A})$ & $d(\mathrm{D} \cdots \mathrm{A})$ & $<(\mathrm{DHA})$ \\
\hline $\mathrm{O}(1)-\mathrm{H}(5) \cdots \mathrm{O}(3) \# 2$ & $0 \cdot 71(3)$ & $2 \cdot 03(3)$ & $2 \cdot 730(2)$ & $168(3)$ \\
\hline $\mathrm{O}(1)-\mathrm{H}(6) \cdots \mathrm{O}(4) \# 3$ & $0 \cdot 70(3)$ & $1.92(4)$ & $2 \cdot 623(2)$ & $176(4)$ \\
\hline $\mathrm{O}(2)-\mathrm{H}(7) \cdots \mathrm{O}(3) \# 4$ & $0 \cdot 80(4)$ & $2 \cdot 18(4)$ & $2 \cdot 961(3)$ & $163(3)$ \\
\hline $\mathrm{O}(2)-\mathrm{H}(8) \cdots \mathrm{O}(4) \# 5$ & $0 \cdot 75(4)$ & $2 \cdot 08(4)$ & $2 \cdot 827(3)$ & $175(4)$ \\
\hline
\end{tabular}

Symmetry transformations used to generate equivalent atoms:

$\# 1-x,-y,-z \# 2-x+1,-y+1,-z+1 \# 3 x-1, y, z-1 \# 4-x+1,-y,-z+1 \# 5-x,-y,-z+1$

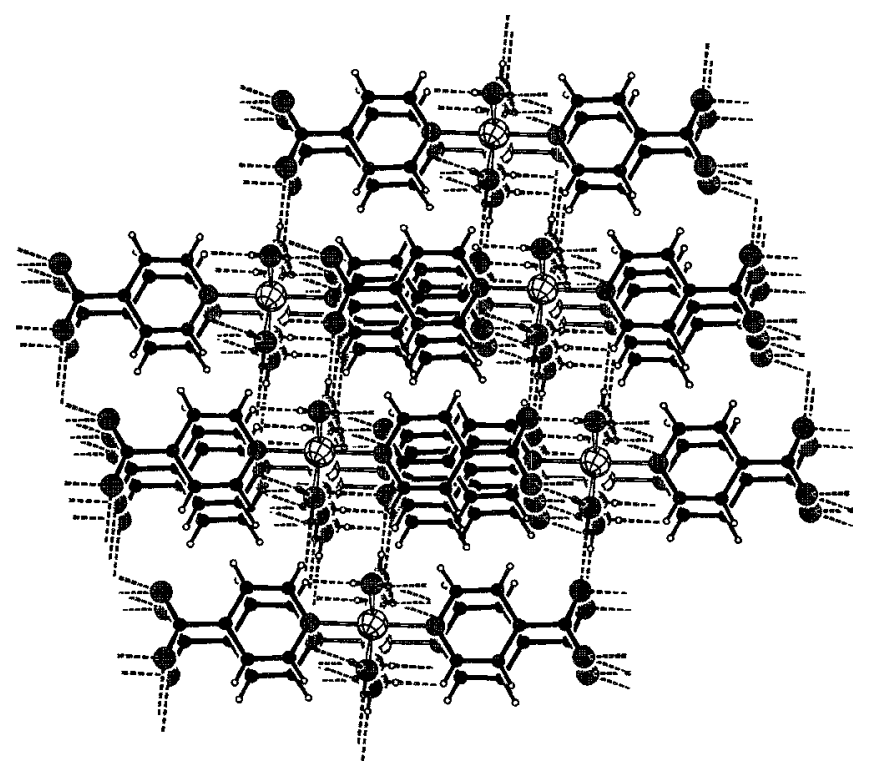

Figure 2. Supramolecular structure of $\mathrm{Cu}\left(\mathrm{C}_{6} \mathrm{H}_{4} \mathrm{O}_{2} \mathrm{~N}\right)_{2}$ $\left(\mathrm{H}_{2} \mathrm{O}\right)_{4}$ showing the location of hydrogen bonds between coordinated water molecules and the uncoordinated carboxyl groups of the isonicotinato ligands.

Table 2 also indicates the presence of four distinct hydrogen bonds in the crystal structure of $\mathrm{Cu}\left(\mathrm{C}_{6} \mathrm{H}_{4} \mathrm{O}_{2} \mathrm{~N}\right)_{2}\left(\mathrm{H}_{2} \mathrm{O}\right)_{4}$ and its structural analogues. The crystal packing diagram of $\mathrm{Cu}\left(\mathrm{C}_{6} \mathrm{H}_{4} \mathrm{O}_{2} \mathrm{~N}\right)_{2}$ $\left(\mathrm{H}_{2} \mathrm{O}\right)_{4}$ shown in figure 2 indicates the hydrogen bond links that form this supramolecular coordination solid and its analogues.
As shown in figure 2, hydrogen bonds supramolecularly join the molecules into layers that are interconnected through further hydrogen bonds to lead to a robust 3-D architecture. One notable feature of the crystal structures of metal isonicotinate tetrahydrates is that all the available hydrogen bond acceptor and donor sites participate in hydrogen bond formation. The $\mathrm{O}-\mathrm{H} . . . \mathrm{O}$ bond lengths and angles listed in table 2 indicate that their shortness coupled with near-linearity results in strong hydrogen-bonding interactions leading to stability against the loss of coordinated water molecules.

\subsection{UV-visible-NIR spectroscopy}

In view of the poor solubility of these coordination solids in water and common organic solvents, the metal isonicotinate tetrahydrates could not be studied by UV-visible absorption spectroscopy in solution. Accordingly, the UV-visible-NIR spectra for the compounds were obtained in the diffuse reflectance mode, but plotted in the absorption mode by applying Kubelka-Munk relation ${ }^{19}$ between reflectance and absorption. The spectral data may be interpreted in terms of ligand field theory coupled with the invocation of ligand based as well as metal-ligand charge transfer transitions. The electronic spectra of the complexes are presented in figures 3-8.

In the UV-Vis-NIR spectrum of $\mathrm{Mn}\left(\mathrm{C}_{6} \mathrm{H}_{4} \mathrm{O}_{2} \mathrm{~N}\right)_{2}$ $\left(\mathrm{H}_{2} \mathrm{O}\right)_{4}$ no $d-d$ band of note is observed for $d^{5}-\mathrm{Mn}^{2+}$ 
because all electronic transitions from the ${ }^{6} A_{1 g}$ ground state are doubly forbidden. The shoulder around $320 \mathrm{~nm}$ may be of MLCT origin, while the twin absorptions at 226 and $273 \mathrm{~nm}$ have origins in the $\pi \rightarrow \pi^{*}$ absorption of the pyridine-based isonicotinato ligand. This so-called $\pi \rightarrow \pi^{*}$ band of pyridine itself appears at $257 \mathrm{~nm}$ with $\varepsilon=2,750 \mathrm{M}^{-1} \mathrm{~cm}^{-1}$. For sodium isonicotinate in aqueous medium, this band appears at $265 \mathrm{~nm}$. Appearance of two nearly equal-intensity bands for $\mathrm{Mn}\left(4-\mathrm{pyCO}_{2}\right)_{2}\left(\mathrm{H}_{2} \mathrm{O}\right)_{4}$ may be due to solid-state effects. Even otherwise, this band for pyridine and substituted pyridines is known to display vibrational fine structure. Indeed the presence of more than one pyridine $\pi \rightarrow \pi^{*}$ absorption is

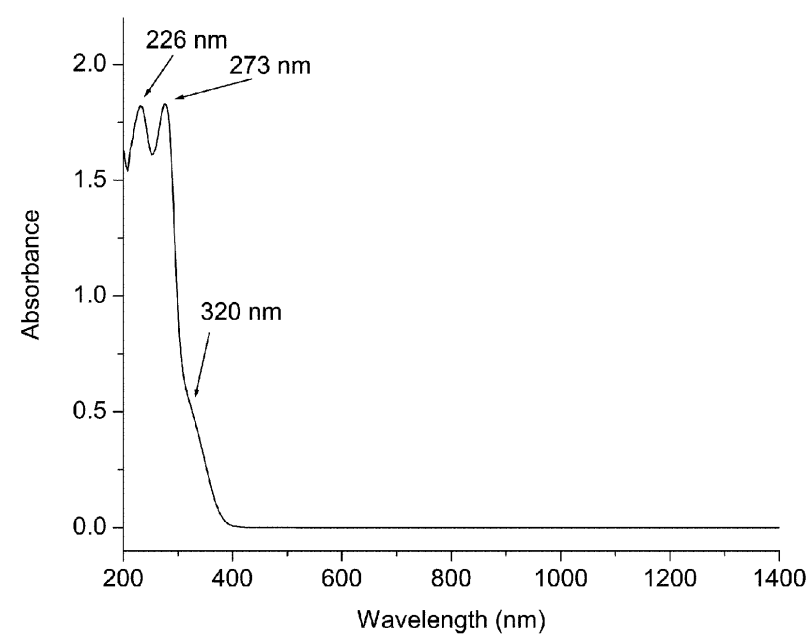

Figure 3. Diffuse reflectance UV-visible-NIR spectrum of $\mathrm{Mn}\left(\mathrm{C}_{6} \mathrm{H}_{4} \mathrm{O}_{2} \mathrm{~N}\right)_{2}\left(\mathrm{H}_{2} \mathrm{O}\right)_{4}$.

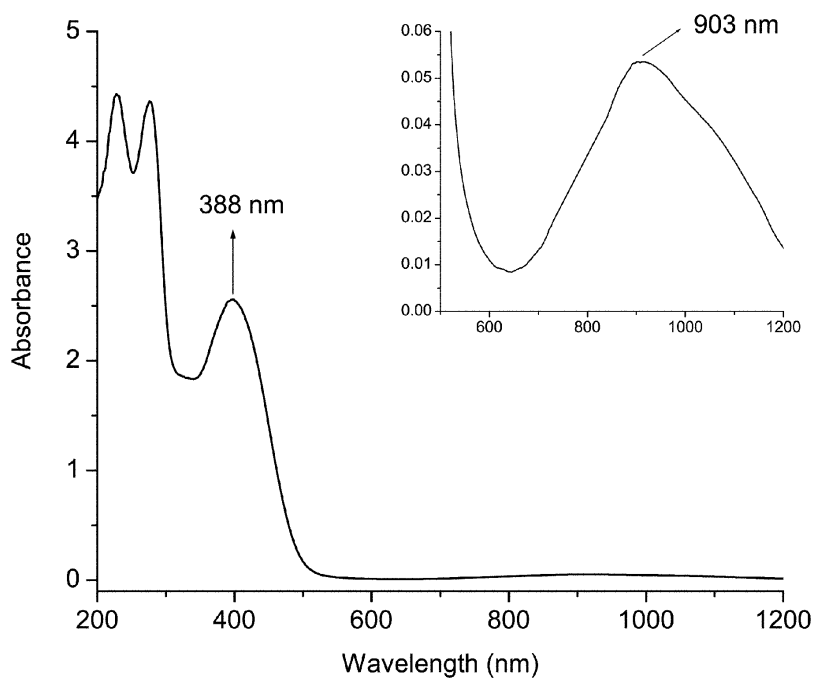

Figure 4. Diffuse reflectance UV-visible-NIR spectrum of $\mathrm{Fe}\left(\mathrm{C}_{6} \mathrm{H}_{4} \mathrm{O}_{2} \mathrm{~N}\right)_{2}\left(\mathrm{H}_{2} \mathrm{O}\right)_{4}$.

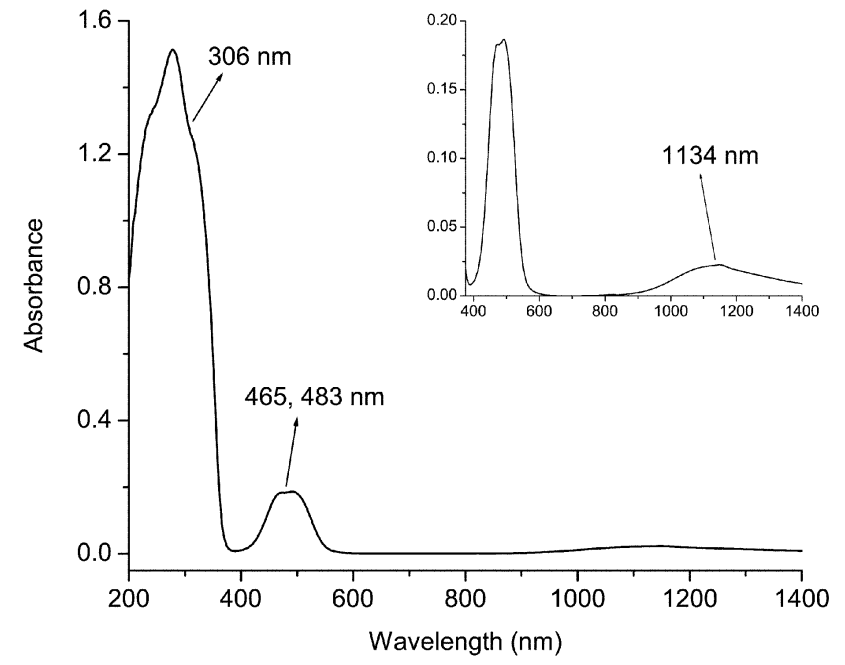

Figure 5. Diffuse reflectance UV-visible-NIR spectrum of $\mathrm{Co}\left(\mathrm{C}_{6} \mathrm{H}_{4} \mathrm{O}_{2} \mathrm{~N}\right)_{2}\left(\mathrm{H}_{2} \mathrm{O}\right)_{4}$.
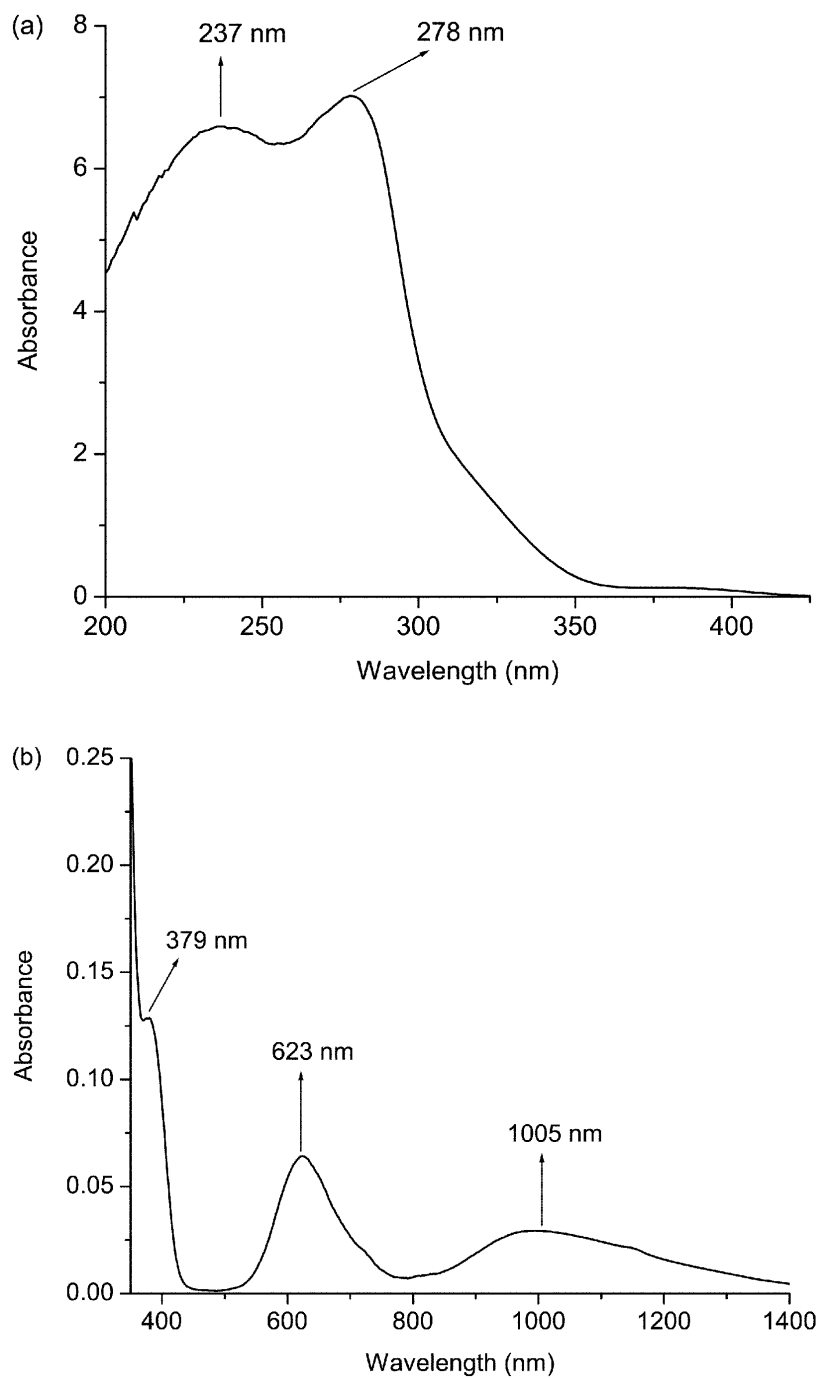

Figure 6. Diffuse reflectance (a) UV and (b) visibleNIR spectra of $\mathrm{Ni}\left(\mathrm{C}_{6} \mathrm{H}_{4} \mathrm{O}_{2} \mathrm{~N}\right)_{2}\left(\mathrm{H}_{2} \mathrm{O}\right)_{4}$. 
a common feature of the diffuse reflectance UV spectrum of the $\mathrm{M}\left(4-\mathrm{pyCO}_{2}\right)_{2}\left(\mathrm{H}_{2} \mathrm{O}\right)_{4}$ compounds, as will be seen presently.

The spectrum of the iron complex is more interesting. Although the majority of iron(II) complexes are lightly coloured or not coloured at all, this particular compound is bright yellow in colour. The yellow colour of the $\mathrm{Fe}$ (II) complex is caused by the absorption at $388 \mathrm{~nm}$ due to an MLCT transition involving a filled metal $d$ orbital and a pyridine $\pi^{*}$ orbital. The $903 \mathrm{~nm}$ band is assigned to the ${ }^{1} A_{1 g} \rightarrow$ ${ }^{1} T_{1 g}$ transition of the low-spin $d^{6}-\mathrm{Fe}^{2+}$ octahedral

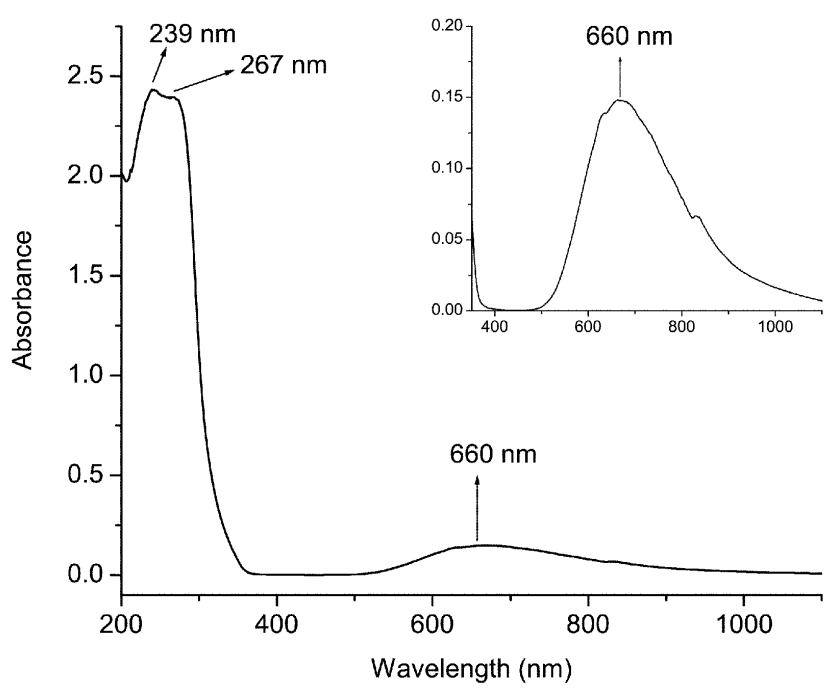

Figure 7. Diffuse reflectance UV-visible-NIR spectrum of $\mathrm{Cu}\left(\mathrm{C}_{6} \mathrm{H}_{4} \mathrm{O}_{2} \mathrm{~N}\right)_{2}\left(\mathrm{H}_{2} \mathrm{O}\right)_{4}$.

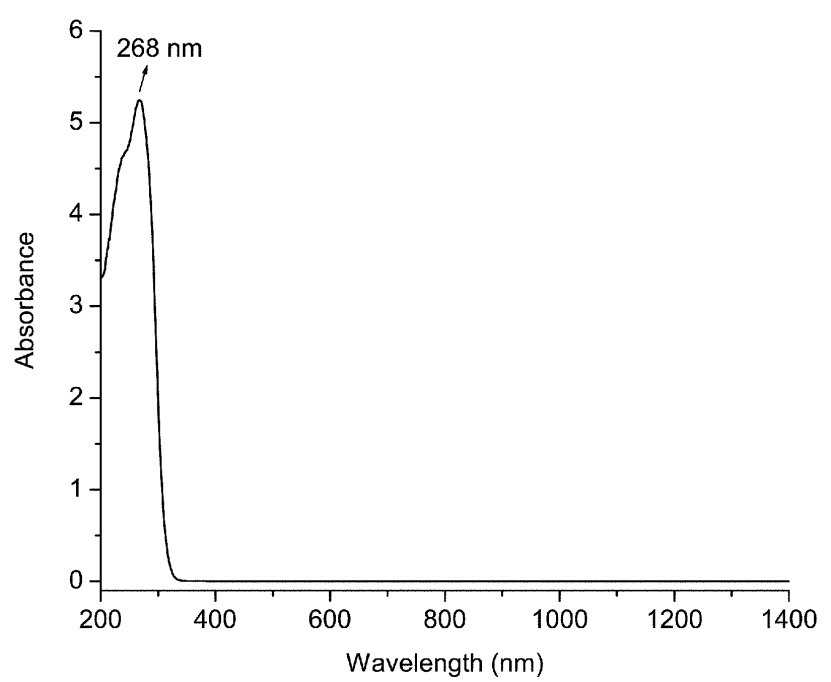

Figure 8. Diffuse reflectance UV-visible-NIR spectrum of $\mathrm{Zn}\left(\mathrm{C}_{6} \mathrm{H}_{4} \mathrm{O}_{2} \mathrm{~N}\right)_{2}\left(\mathrm{H}_{2} \mathrm{O}\right)_{4}$. complex. Owing to this particular ligand field band that occurs in the NIR region, most $\mathrm{Fe}(\mathrm{II})$ complexes are colourless in absence of other transitions absorbing in the visible region. The similarity of absorption envelope of the broad NIR band due to the low-spin complex $\mathrm{M}\left(4-\mathrm{pyCO}_{2}\right)_{2}\left(\mathrm{H}_{2} \mathrm{O}\right)_{4}$ with the corresponding bands $^{25}$ in the high-spin complexes tetraaquabis (hydrogenmaleato)iron(II), $\mathrm{Fe}\left(\mathrm{C}_{4} \mathrm{H}_{3} \mathrm{O}_{4}\right)_{2}\left(\mathrm{H}_{2} \mathrm{O}\right)_{4}$ and hexaaquairon(II), $\left[\mathrm{Fe}\left(\mathrm{OH}_{2}\right)_{6}\right]^{2+}$, is however rather intriguing.

The spectra recorded for the cobalt complex is shown in figure 5. We expect three ligand field bands for the high spin, octahedral Co(II) complex. The electronic transitions from the ${ }^{4} T_{1 g}(F)$ ground state to ${ }^{4} T_{2 g}(F),{ }^{4} A_{2 g}(F)$, and ${ }^{4} T_{1 g}(P)$ are expected in the spectra of $\mathrm{Co}(\mathrm{II})$ complexes. While the first band occurs at $1134 \mathrm{~nm}$, the third band is seen at $483 \mathrm{~nm}$, and the second band is not seen at all because it is due to a two-electron transition. The $465 \mathrm{~nm}$ transition is owing to a transition to one of the spin-doublet levels, which gains intensity via spin-orbit coupling because of its proximity to the ${ }^{4} T_{1 g}(\mathrm{P})$ state. ${ }^{26}$ The absorption at $306 \mathrm{~nm}$ is due to charge transfer (MLCT).

For the nickel complex we expect three ligand field bands (figure 6). All these are observed. The band assignments for the visible-NIR region are: $985 \mathrm{~nm},{ }^{3} A_{2 g} \rightarrow{ }^{3} T_{2 g}(F) ; 618 \mathrm{~nm},{ }^{3} A_{2 g} \rightarrow{ }^{3} T_{1 g}(F)$; $369 \mathrm{~nm},{ }^{3} A_{2 g} \rightarrow{ }^{3} T_{1 g}(P)$. UV bands originating in the $\pi \rightarrow \pi^{*}$ transition of the pyridine ring are found in the expected positions.

The last of the metal(II) isonicotinate tetrahydrates for which ligand field bands are expected, $\mathrm{Cu}\left(\mathrm{C}_{6} \mathrm{H}_{4} \mathrm{O}_{2} \mathrm{~N}\right)_{2}\left(\mathrm{H}_{2} \mathrm{O}\right)_{4}$, also show UV-visible-NIR spectra along expected lines (figure 7). The broad band due to the ${ }^{2} E_{g} \rightarrow{ }^{2} T_{2 g}(F)$ transition, which gives rise to the characteristic blue colour to copper(II) compounds, is centred at $660 \mathrm{~nm}$. The spectrum of $\mathrm{Zn}\left(\mathrm{C}_{6} \mathrm{H}_{4} \mathrm{O}_{2} \mathrm{~N}\right)_{2}\left(\mathrm{H}_{2} \mathrm{O}\right)_{4}$ shows no bands other than those for the pyridine $\pi \rightarrow \pi^{*}$ transitions (figure 8).

The above description of spectroscopic results clearly suggests that although hexacoordinate metal complexes have two types of ligands, the symmetry of the complexes remain approximately octahedral. For the tetragonally distorted copper compound, Jahn-Teller distortion leads to broadening of the only ligand field band. On the other hand, our results also show that diffuse reflectance spectroscopy provides a good technique for obtaining ligand field spectral information of transition metal complexes, although molar absorptivity cannot be determined by this method. 
Table 3. Gravimetric estimation of $\mathrm{Cu}$ in a few compounds of copper.

\begin{tabular}{lccc}
\hline Sample & Empirical formula & $\%$ of $\mathrm{Cu}$ (calc.) & $\%$ of $\mathrm{Cu}$ (obsd.) \\
\hline $\mathrm{CuSO}_{4} \cdot 5 \mathrm{H}_{2} \mathrm{O}$ & $\mathrm{H}_{10} \mathrm{O}_{9} \mathrm{SCu}$ & $25 \cdot 44$ & $25 \cdot 57( \pm 0 \cdot 11)$ \\
$\mathrm{Cu}_{2}\left(\mathrm{CH}_{3} \mathrm{CO}_{2}\right)_{4} \cdot\left(\mathrm{H}_{2} \mathrm{O}\right)_{2}$ & $\mathrm{C}_{8} \mathrm{H}_{16} \mathrm{O}_{10} \mathrm{Cu}_{2}$ & $31 \cdot 82$ & $31 \cdot 80( \pm 0 \cdot 14)$ \\
$\mathrm{Cu}_{2}\left(\mathrm{C}_{6} \mathrm{H}_{5} \mathrm{CO}_{2}\right)_{4}(4-\mathrm{Etpy})_{2}$ & $\mathrm{C}_{42} \mathrm{H}_{38} \mathrm{~N}_{2} \mathrm{O}_{8} \mathrm{Cu}_{2}$ & $15 \cdot 40$ & $15 \cdot 47( \pm 0 \cdot 13)$ \\
\hline
\end{tabular}
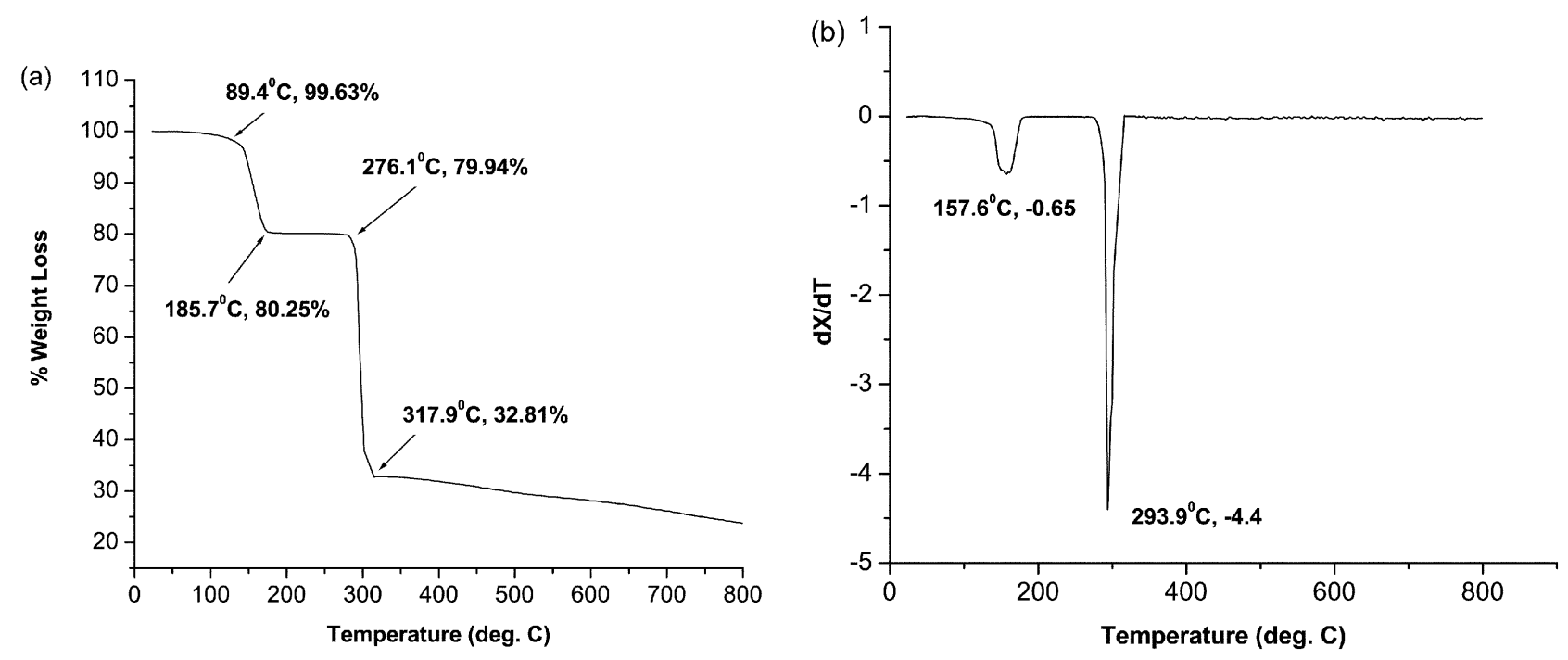

Figure 9. TG (a) and DTG (b) curves of $\mathrm{Cu}\left(\mathrm{C}_{6} \mathrm{H}_{4} \mathrm{O}_{2} \mathrm{~N}\right)_{2}\left(\mathrm{H}_{2} \mathrm{O}\right)_{4}$.

\subsection{Applications in analysis}

Thermogravimetric curves for $\mathrm{Cu}\left(\mathrm{C}_{6} \mathrm{H}_{4} \mathrm{O}_{2} \mathrm{~N}\right)_{2}\left(\mathrm{H}_{2} \mathrm{O}\right)_{4}$ are shown in figure 9. As the $\mathrm{TG}$ curve shows, weight change due to the loss of four-coordinated water molecules occurs between $\sim 90^{\circ} \mathrm{C}$ and $186^{\circ} \mathrm{C}$. The important point to note here is that the weight loss due to dehydration is not significant until about $60^{\circ} \mathrm{C}$, which is in conformity with the indefinite stability of $\mathrm{Cu}\left(\mathrm{C}_{6} \mathrm{H}_{4} \mathrm{O}_{2} \mathrm{~N}\right)_{2}\left(\mathrm{H}_{2} \mathrm{O}\right)_{4}$ at room temperature. Furthermore, the dehydrated product, $\mathrm{Cu}\left(\mathrm{C}_{6} \mathrm{H}_{4} \mathrm{O}_{2} \mathrm{~N}\right)_{2}$ remains stable between $186^{\circ} \mathrm{C}$ and $276^{\circ} \mathrm{C}$. These results suggest that either of the well-defined solids $\mathrm{Cu}\left(\mathrm{C}_{6} \mathrm{H}_{4} \mathrm{O}_{2} \mathrm{~N}\right)_{2}\left(\mathrm{H}_{2} \mathrm{O}\right)_{4}$ or $\mathrm{Cu}\left(\mathrm{C}_{6} \mathrm{H}_{4} \mathrm{O}_{2} \mathrm{~N}\right)_{2}$ may be used for the gravimetric analysis of copper. However, in view of the tendency of rehydration shown by the latter, ${ }^{15}$ we have utilized only the tetrahydrate of copper(II) isonicotinate for gravimetric determination of the copper content in a few compounds of copper. For our preliminary studies on the use of $\mathrm{Cu}\left(\mathrm{C}_{6} \mathrm{H}_{4} \mathrm{O}_{2} \mathrm{~N}\right)_{2}\left(\mathrm{H}_{2} \mathrm{O}\right)_{4}$ for gravimetric determination of copper, we have used samples of $\mathrm{CuSO}_{4} \cdot 5 \mathrm{H}_{2} \mathrm{O}$, $\mathrm{Cu}_{2}\left(\mathrm{CH}_{3} \mathrm{CO}_{2}\right)_{4} \cdot\left(\mathrm{H}_{2} \mathrm{O}\right)_{2}$ and $\mathrm{Cu}_{2}\left(\mathrm{C}_{6} \mathrm{H}_{5} \mathrm{CO}_{2}\right)_{2}$ (4-ethylpyridine $)_{2}$, the last one being a new compound pre-

pared in this laboratory. ${ }^{27}$ Results are based on three independent measurements (table 3).

The data shown above suggest that the accuracy of the results based on weighing of copper as $\mathrm{Cu}$ (isonicotinate) $)_{2} \cdot 4 \mathrm{H}_{2} \mathrm{O}$ is comparable to those that can be obtained by using established analytical methods such as iodometry and gravimetry involving $\mathrm{CuSCN}$ as the precipitate.

\section{Conclusion}

A convenient method for synthesizing metal isonicotinate tetrahydrates has been developed. Crystal structure analyses show that the compounds are molecular; however, due to the presence of hydrogen bond donor and acceptor sites in the complexes, a robust supramolecular hydrogen bonded network is present in the crystals. Despite presence of two different types of ligands, these compounds behave as octahedral complexes in the solid state as indicated by their electronic spectra. [Fe(isonicotinate $)_{2}$ $\left.\left(\mathrm{OH}_{2}\right)_{4}\right]$ contains $\mathrm{Fe}(\mathrm{II})$ in the low-spin diamagnetic state. Poor solubility of the complexes in water cou- 
pled with thermal stability of the complexes over a wide range of temperatures suggests their application in gravimetric determination of the metals.

\section{Acknowledgements}

The authors would like to thank the University Grants Commission, Govt of India for financial support. We are also thankful to Prof M G Kanatzidis of the Department of Chemistry, North Western University, USA for his support to BKD.

\section{Supplementary materials}

The structural results in .cif format are available in the net version. The crystal structure has been deposited at CCDC 628462.

\section{References}

1. Huheey J E, Keiter E A and Keiter R L 1993 Inorgnaic chemistry: Principles of structure and reactivity, 4th edn (HarperCollins College Publishers) NY

2. Desiraju G R (ed.) 1996 The crystal as a supramolecular entity (Chichester: John Wiley \& Sons)

3. Moulton B and Zaworotko M J 2001 Chem. Rev. 101 1629

4. Braga D and Grepioni F 2000 Acc. Chem. Res. 33 601

5. Beatty A M 2001 Cryst. Eng. Commun. 511

6. Wei Q, Nieuwenhuyzen M, Meunier F, Hardacre C and James S L 2004 J. Chem. Soc., Dalton Trans. 1807 and references therein

7. Chapman M E, Ayyappan P, Foxman B M, Yee G T and Lin W 2001 Cryst. Growth Des. 2159
8. Waizumi K, Takuno M, Fukushima $\mathrm{N}$ and Masuda $\mathrm{H}$ 1998 J. Coord. Chem. 44269

9. Evans O R, Xiong R-G, Wang Z, Wong G K and Lin W 1999 Angew. Chem., Int. Ed. Engl. 38536

10. Ma T-H, Yu J-H, Ye L, Xu J-Q, Wang T-G and Lü C-H 2003 J. Mol. Struct. 65447

11. Lu J Y and Babb A M 2002 Chem. Commun. 1340

12. Hauptman R, Kondo M and Kitagawa S 2000 Z. Kristallogr. 215171

13. Liu Q, Wei Y, Wang W and Zhang S 1999 Acta Crystallogr. C55 IUC9900127

14. Yan Z-Q 2004 Acta Crystallogr. E60 m116

15. Lin C Z-J, Chui S S-Y, Lo S M-F, Shek F L-Y, Wu M, Suwinska K, Lipkowski J and Williams I D 2002 Chem. Commun. 1642

16. Choi K-Y, Kima M-J and Suhb I-H 2002 Korean J. Crystallogr. 1317

17. Bora S J and Das B K (unpublished result)

18. Sileo E E, Morando P J, Della Vedova C O and Blesa M A 1989 Thermochim. Acta 138233

19. (a) Perkampus H-H 1993 in Encyclopaedia of spectroscopy (Translators: Grinter $\mathrm{H}-\mathrm{C}$ and Grinter R) (Weinheim: VCH); (b) Kortüm G 1969 Reflectance spectroscopy (Berlin: Springer Verlag)

20. SMART 1994 Siemens Analytical X-ray System, Inc., Madison, WI

21. SAINT 1994 Version 4: Siemens Analytical X-ray System, Inc., Madison, WI

22. SADABS: 1996 Sheldrick G M, University of Göttingen, Germany

23. Sheldrick G M 1997 SHELX-97: A program for the solution and refinement of crystal structures, University of Göttingen: Germany

24. Faruggia L 1999 J. Appl. Crystallogr. 32837

25. Barman R K, Chakrabarty R and Das B K 2002 Polyhedron 211189

26. Figgis B N and Hitchman M A 2000 Ligand field theory and its applications (New York: Wiley-VCH) p. 209

27. Sarmah P, Bora S J and Das B K (unpublished result) 